\title{
Comunicação
}

[Communication]

\section{Ocorrência de oocistos de Cryptosporidium spp. em águas superficiais na região metropolitana de Recife-PE}

[Occurrence of Cryptosporidium spp. oocysts in surface water from Recife Metropolitan area, Brazil]

\author{
E.C.L. Machado ${ }^{1}$, T.L.M. Stamford ${ }^{1 *}$, E.H.L. Machado ${ }^{2}$, D.S. Soares ${ }^{1}$, M.N.L. Albuquerque ${ }^{1}$ \\ ${ }^{1}$ Departamento de Nutrição - CCS-UFPE - Recife, PE \\ ${ }^{2}$ Médico veterinário autônomo
}

Diante do cenário das doenças provocadas por protozoário que tem veiculação hídrica no Brasil, a criptosporidiose apresenta papel de destaque. Das espécies conhecidas, Cryptosporidium parvum e C hominis (antes reconhecida como genótipo 1 de $C$. parvum) são frequentemente associadas à infecção no homem, embora haja relatos de casos humanos com $C$. muris, $C$. meleagridis, C. canis, $C$. felis, genótipos cervine e pig (Xiao et al., 2004). Esse parasita produz oocistos resistentes às condições ambientais e, dessa forma, podem ser veiculados por água e alimentos contaminados e atingir um grande contingente da população. Quando em material fecal ou na água, podem reter a sua infectividade por vários meses (Smith, 1998; Carey et al., 2004).

Há vários relatos de ocorrência de Cryptosporidium spp. no ambiente aquático de diferentes regiões no mundo. No Brasil, a preocupação com a presença do parasito em água de consumo humano, é retratada pela portaria 518/MS (Portaria..., 2004), e os oocistos têm sido identificados nos estados de São Paulo, Minas Gerais e Ceará, sendo encontrados em águas superficiais, bruta e tratada, águas minerais engarrafadas, em poços, esgotos tratados ou não, lodo ativado (Machado, 2006), e em estuários de peixe-boi marinho (Borges, 2007).

Assim, este trabalho teve o objetivo de estudar a ocorrência de oocistos de Cryptosporidium spp. em águas brutas superficiais destinadas ao tratamento convencional e em água após o seu tratamento completo, no período de setembro de 2003 a agosto de 2004.

A estação de tratamento de água (ETA) Presidente Castelo Branco, que abastece 36\% da Região Metropolitana de Recife, realiza o tratamento convencional (mistura com carvão ativado e coagulação com sulfato de alumínio, seguidos pela floculação, decantação, filtração em filtros de areia e desinfecção com cloro) das águas captadas de diferentes mananciais incluindo o rio Tapacurá, o rio Capibaribe e o rio Duas Unas, com capacidade nominal de tratamento de $4 \mathrm{~m}^{3} / \mathrm{s}$. Os maiores mananciais (rio Tapacurá e seu afluente várzea do Una) pertencem à bacia do rio Tapacurá, que envia água para essa região em mais de $25 \%$ da oferta (Braga, 2001).

Amostras de águas superficiais, analisadas durante 12 meses, nos períodos de seca (setembro a fevereiro) e chuvoso (março a agosto), foram coletadas com galões de cinco litros em pontos de captação existentes nos mananciais (rio Tapacurá, rio Capibaribe em Tiúma, rio Capibaribe em Castelo, rio Duas Unas), e na entrada e saída do sistema de tratamento (água bruta e água tratada, respectivamente), totalizando cinco locais de coleta de água bruta com 60 amostras e 12 amostras de água tratada coletadas na saída do sistema de tratamento da ETA.

As amostras foram filtradas sob pressão negativa usando membranas de ésteres de celulose $(47 \mathrm{~mm}$

Recebido em 18 de agosto de 2008

Aceito em 16 de setembro de 2009

* Autor para correspondência (corresponding author)

E-mail: tlmstamford@yahoo.com.br 
de diâmetro e $3 \mu \mathrm{m}$ de porosidade nominal). Para a concentração dos oocistos, foi usada a metodologia descrita em Aldom e Chagla (1995) com modificação na etapa de dissolução da membrana em acetona, a qual foi eluída com solução de dodecil sulfato de sódio (1\%) e Tween $80(1 \%)$ e auxílio de uma espátula plástica para raspagem de sua superfície (Franco et al., 2001). O volume resultante foi centrifugado (605 x g; 10 minutos) e posteriormente sucessivas centrifugações foram realizadas com álcool $95 \%$ e $70 \%$, para ressuspender os sedimentos. Duas alíquotas de $5 \mu \mathrm{L}$ do sedimento final foram colocadas em lâminas. Para a pesquisa de Cryptosporidium spp., foi usada a técnica IFD conforme recomendações do fabricante do kit Merifluor ${ }^{1}$, mas associado ao corante 4'6'-diamidino-2phenylindole ${ }^{2}$ (Smith et al., 2002).

O cálculo do número médio de oocistos por litro (X) foi realizado de acordo com a fórmula descrita por Cantusio Neto e Franco (2004).

Para o teste controle do sistema de filtração, foram usadas amostras de água bruta (entrada) e tratada (saída do sistema de tratamento), e água destilada como controle negativo, sendo o ensaio realizado em duas repetições para cada tipo de amostra de água. Oocistos de Cryptosporidium spp. foram gentilmente cedidos pelo setor de parasitologia do Laboratório Central do Estado, sendo purificados por meio da centrífugoflutuação com solução saturada de $\mathrm{NaCl}(1,2 \mathrm{~g}$ $\mathrm{mL}^{-1}$ ), conforme Machado (2006), quantificados após coloração pela técnica de Kinyoun e conservados em formol a $10 \%$ sob refrigeração. Seguindo o protocolo do método 1622 da USEPA (Method..., 2001), as amostras de água tratada e água bruta foram inoculadas com um número estimado de $1,5 \times 10^{2}$ oocistos/L. A determinação da eficiência de recuperação $(\mathrm{R})$ baseou-se no método 1622 (Method..., 2001), considerando o número de oocistos presentes na amostra inoculada (I) e sem inoculação (S) e o número de oocistos inoculados $(\mathrm{O})$, por meio da seguinte fórmula:

$\mathrm{R}=\frac{\mathrm{I}-\mathrm{S}}{\mathrm{O}} \times 100$

${ }^{1}$ Meridian Bioscience Diagnostics, Cincinnatti, EUA. ${ }^{2}$ DAPI-Sigma ${ }^{\circledR}$ - S. Louis, EUA.
As análises de coliformes totais e termotolerantes, e físico-químicas (turbidez e $\mathrm{pH})$ foram realizadas conforme metodologia descrita no APHA (Standard..., 1998). Dados de precipitação pluviométrica no período do estudo foram obtidos no Laboratório de Meteorologia de Pernambuco (ITEP/PE).

As amostras de água tratada não apresentaram positividade nas análises parasitológicas, enquanto nas amostras de água bruta foram encontrados em 40\% (02/05) dos locais e em 5\% (03/60) das amostras, com o número de oocistos variando de 16 oocistos/L (rio Capibaribe em Tiúma) a 40 oocistos/L, em duas amostras do rio Tapacurá.

Considerando que o princípio da técnica IFD depende da formação do complexo antígenoanticorpo, comenta-se que a presença de resíduos na amostra pode impedir a marcação fluorescente dos oocistos, no entanto, no presente estudo, a amostra do Rio Capibaribe em Tiúma, positiva para o parasito, apresentou turbidez elevada de 73,9 unidades nefelométricas de turbidez (UNT). Atualmente, para minimizar esta interferência, é recomendada a purificação da amostra, previamente ao diagnóstico por IFD ou PCR (Standard..., 2005). Outros fatores podem ser inerentes ao próprio oocisto de origem ambiental, uma vez que a formação desse complexo depende da integridade do oocisto (Smith, 1998).

Quando identificados pelo DAPI na amostra do rio Capibaribe em Tiúma, os oocistos apresentaram dois esporozoítos, enquanto nas amostras do rio Tapacurá não apresentaram esporozoítos. Smith et al. (2002) verificaram que os oocistos apresentavam números intermediários de esporozoítos, diferentes de zero e quatro, além de que oocistos vazios também foram mais frequentes. Isso vem reforçar que oocistos de origem ambiental, com mais tempo de vida, podem diferir de oocistos fecais recentemente eliminados quanto à habilidade de manter-se intacto, e serem mais sujeitos a alterações físicas. Vale salientar que oocistos vazios são indicativos de contaminação (Smith, 1998; Smith et al., 2002).

Todas as amostras de água bruta encontraram-se dentro dos padrões da classe II (Resolução ..., 2005), assim com as de água tratada atenderam às exigências da Portaria 518/MS (Portaria..., 
2004), exceto quanto à turbidez, quando em 12 amostras de água bruta o resultado variou de 42,2 a 106UNT (padrão: 40UNT máx.), das quais apenas uma apresentou positividade para Cryptosporidium spp.; e em cinco amostras de água tratada variou de 1,76 a 2,9UNT (padrão máximo: 1,0UNT).

Neste estudo, verificou-se a ocorrência de oocistos de Cryptosporidium spp. no período seco (rio Capibaribe em Tiúma) e chuvoso (rio Tapacurá). Vale salientar que os índices de precipitação pluviométrica representaram adequadamente as estações climáticas, de forma que foi maior no período chuvoso. Poucas são as informações sobre a influência climática desse parasito no ambiente aquático.

A presença de Cryptosporidium spp. nas águas superficiais depende do potencial das fontes de contaminação do ambiente aquático, e a sua detecção, muitas vezes, está relacionada à área geográfica selecionada para o estudo, ou ainda, à eficiência da metodologia empregada. É importante informar que as amostras-controle neste estudo apresentaram um percentual de oocistos recuperados, de $33,05 \%$ e de $22,03 \%$ na água tratada $(0,7 \mathrm{UNT}, \mathrm{pH}=6,8)$ e bruta (67,7UNT, $\mathrm{pH}=7,2)$, respectivamente. Ainda, verificou-se um curral de bovinos de localização ribeirinha e próximo ao ponto de captação do rio Tapacurá, o que aumenta a probabilidade de escoamento de oocistos (Fraser et al., 1998), além de outras fontes citadas por Braga (2001).

Tsushima et al. (2003) comentaram que o aumento no número de oocistos nos rios pode ter sido influenciado pelo maior fluxo de animais no local e pelos maiores índices de precipitação pluviométrica. Hansen e Ongerth (1991) verificaram uma concentração de oocistos dez vezes mais elevada quando houve influência do gado bovino na contaminação aquática. Cardoso et al. (2003) citaram que a frequência de amostras positivas foi aproximadamente duas vezes mais alta em águas superficiais de áreas agrícolas, e seis vezes mais alta em áreas com potencial impacto de efluentes, quando comparado com zonas de nascentes.

Este é o primeiro relato de Cryptosporidium spp. em mananciais de Pernambuco e do Nordeste.

Palavras-chave: oocisto, protozoário, água

\begin{abstract}
The occurrence of Cryptosporidium spp. in superficial waters at the Metropolitan Region of Recife, PE, was studied. Raw and treated water were analyzed by filtration of the samples on a membrane (47mm, $3 \mu \mathrm{m})$ under negative pressure, by the direct immunofluorescence assay (IFA), and by the 4'6'-diamidino-2-phenylindole (DAPI) method. The samples were analyzed during drought (September to February) and raining (March to August) seasons. Oocysts were not found in treated water. Cryptosporidium spp. oocysts were found in nontreated water by IFA/DAPI technique in 40\% (2/5) of the locations and in $5 \%(3 / 60)$ of the samples investigated, with the number varying from 16 oocysts/l to 40/l, in dry and raining seasons, respectively. This is the first report of Cryptosporidium spp. in surface water in the state of Pernambuco, Northeast of Brazil.
\end{abstract}

Keyword: oocyst, protozoon, water

\section{REFERÊNCIAS BIBLIOGRÁFICAS}

ALDOM, J.E; CHAGLA, A.H. Recovery of Cryptosporidium spp. oocysts from water by a membrane filter dissolution method. Lett. Appl. Microbiol., v.20, p.186-187, 1995.

BORGES J.C.G. Cryptosporidium spp. (Tyzzer, 1907) em peixes-boi marinhos (Trichechus manatus) (Linnaeus, 1758) e peixes-boi amazônicos (Trichechus inunguis) (Natterer, 1883) no Brasil. 2007. 121f. Dissertação (Mestrado) - Universidade Federal Rural de Pernambuco, Recife.
BRAGA, R.A.P. Gestão ambiental da Bacia do Rio Tapacurá: Plano de ação. Recife: Ed. Universitária UFPE, 2001.

CANTUSIO-NETO, R.; FRANCO, R.M.B. Ocorrência de oocistos de Cryptosporidium spp. e cistos de Giardia spp. em diferentes pontos do processo de tratamento de água, em Campinas, São Paulo, Brasil. Hig. Alim., v.18, p.52-59, 2004. 
CARDOSO, L.S.; DE CARLI, G.A.; DE LUCA, S.J. Cryptosporidium e Giardia em efluentes biologicamente tratados e desinfetados. Eng Sanit $A m b .$, v.8, p.285-290, 2003.

CAREY, C.M.; LEE, H.; TREVORS J.T. Biology, persistence and detection of Cryptosporidium parvum and Cryptosporidium hominis oocyst. Water Res., v.38, p.818-862, 2004.

FRANCO, R.M.B.; ROCHA-EBERHARDT, R.; CANUSIO NETO, R. Occurrence of Cryptosporidium spp. oocysts and Giardia cysts in raw water from Atibaia River, Campinas, Brazil. Rev. Inst. Med. Trop. São Paulo, v.43, p.109-111, 2001.

FRASER, R.H.; BARTEN, P.K.; PINNEY, D.A.K. Predicting stream pathogen loading form livestock using a geographical information system-based delivery model. J. Environ. Qual., v.27, p.935-945, 1998.

HANSEN, J.S.; ONGERTH, J.E. Effects of time and watershed characteristics on the concentration of Cryptosporidium oocysts in river water. Appl. Environ. Microbiol., v.57, p.2790-2795, 1991

MACHADO, E.C.L. Ocorrência de oocistos de Cryptosporidium spp. em águas superficiais na região metropolitana de Recife/PE. 2006. 141f. Tese (Doutorado) - Universidade Federal Pernambuco, Recife.

METHOD 1622: cryptosporidium in water by filtration/IMS/FA. Washington, DC: Environmental Protection Agency/Office of Water, 2001. 51p. (EPA-821-R-99-061).

PORTARIA $\mathrm{n}^{\circ}$ 518. Regulamenta os procedimentos e responsabilidades relativos ao controle e vigilância da qualidade da água para o consumo humano e seu padrão de potabilidade, e dá outras providências [do Ministério da Saúde]. Diário Oficial da União, Brasília, DF, 25 mar. 2004.
RESOLUÇÃO $\mathrm{n}^{\mathrm{o}}$ 357. Regulamenta a classificação dos corpos de água e diretrizes ambientais para o seu enquadramento, bem como estabelece as condições e padrões de lançamento de efluentes, e dá outras providências. [do Conselho Nacional do Meio Ambiente]. Diário Oficial da União, Brasília, DF, 18 mar. 2005. Seção 1, p.58-63.

SMITH, H.V. Detection of parasites in the environment. Parasitology, v.117, suppl., p.S113-S141, 1998.

SMITH, H.V.; CAMPBELL, B.M.; PATON, C.A. et al. Significance of enhanced morphological detection of Cryptosporidium spp. oocysts in water concentrates determined by using 4',6' -diamidino-2-phenylindole and immunofluorescence microscopy. Appl. Environ. Microbiol., v.68, p.5198-5201, 2002.

STANDARD methods for the examination of water and wastewater. 20.ed. Baltimore, MD: American Public Health Association, 1998.

STANDARD methods for the examination of water and wastewater. 20.ed. Baltimore: American Public Health Association, 2005.

TSUSHIMA, Y.; KARANIS, P.; KAMADA, T. et al. Seasonal change in the number of Cryptosporidium parvum oocysts in water samples from the rivers in Hokkaido, Japan, detected by he ferric sulfate flocculation method. J. Vet. Med. Sci., v.65, p.121-123, 2003.

XIAO, L.; FAYER, R.; RYAN, U. et al. Cryptosporidium spp. taxonomy: recent advances and implications for public health. Clin. Microbiol. Rev., v.17, p.72-97, 2004. 